\title{
Compressive failure of concrete tunnel lining simulated by different compressive models
}

\author{
各種圧縮モデルの適用によるコンクリートトンネル覆工の圧縮破壊性状 \\ Wei He*, Zhishen Wu* Jun Yin** and Yoshiyuki Kojima*** \\ 何 偉 吳 智深殷 峻小島 芳之 \\ *Dept. of Urban \& Civil Eng., Ibaraki University \\ (4-12-1, Nakanarusawa-cho, Hitachi, Ibaraki 316-8511) \\ ** Adv. Simulation Tech. Of Mechanics Co., Ltd. (ASTOM) \\ (2-1 Hirasawa, Wako-shi, Saitama 351-0198) \\ *** Structural Technique Development Division, Railway Technical Institute \\ (Kokubunji 2-8-38, Tokyo 185)
}

\begin{abstract}
Concrete tunnel linings under service are subjected to the soil constraint of ground. The deformation characteristics and load-carrying capacity of tunnel linings are clearly varied with the soil constraint. Moreover, due to the soil constraint, the final failure is often dominated by the compressive behavior of concrete. Then for the adoption of a rational compressive model of concrete is considered to be very important for evaluating the structural performance of concrete tunnel linings. Based on this consideration, the effectiveness and efficiency of different compressive models, such as ideal elastic-plastic compressive model and parabolic compressive softening model, are discussed in this paper. It is pointed that parabolic compressive softening model with a consideration of compressive fracture energy is more appropriate to analyze the compressive behavior of concrete tunnel than ideal elastic-plastic compressive model.
\end{abstract}

Key Words: concrete tunnel linings, soil constraint, compressive model, strain softening

\section{Introduction}

There are more and more concrete tunnels in modern highways and railways, but there exist some problems with these tunnels. For example, earthquake, slope terrain or construction of buildings neighborhood will bring increment of load which acts on tunnel, this results in further deformation of tunnel. In addition, wicked geologic conditions, such as wicked bedrock and expansile clay influenced by underground water, may bring expansion of plastic area around tunnel linings and make tunnel linings unstable. Therefore, there exist serious problems of how to efficiently inspect, diagnose and repair them to extend the service life of concrete tunnel.

Although these problems have drawn much attention to designers and researchers in the engineering field and some measurements have been adopted for the practical applications, many current methods for evaluating the conditions of the existing tunnel linings are still on the stage of qualitative analysis. It's necessary to establish the proper quantitative standard of designing the new tunnel linings and of maintaining the existing ones under various service conditions. In recent years, the scale model experiments, such as experiments on $1 / 30$ and $1 / 3$ scale model of plain concrete tunnel lining( Asakura et al., 1997,1998) $)^{1)}$, have been carried out to study the mechanism of tunnel deformation and the reinforcing effect of externally bonded fiber plastic sheets or steel plates, through which much valuable data have been obtained. However, the experimental method alone is still far from sufficiency. It is difficult to simulate some complicated cases. Hence, the analysis with some proper numerical models is becoming an indispensable tool. Some researchers have done effective work on numerical analysis of concrete tunnel, for example, Yin et al. (2001) simulated the crack behavior of concrete tunnel lining by smeared crack model (SCM) based on finite element code $^{2)}$.

Actually tunnel linings in practical service sometimes 
are entirely or partially underground, such as tunnel through mountain, seabed or slope, and so on. In these cases, soil constraint which acts on tunnel cannot be neglected, and the deformation characteristics of tunnel linings with soil constraint are also different from those without soil constraint, the concrete tunnel lining may be subjected to compressive failure. At the same time, the study on the cracking behavior of concrete tunnel lining with soil constraint seems insufficient recent years, so some compressive models based on total strain will be discussed in this paper.

\section{Compressive Failure Modes of Concrete Tunnel}

Under practical engineering geological and loading conditions, there are three main compressive failure modes of concrete tunnel, which are called plastic compressive failure, relaxed compressive failure and deflective compressive failure respectively, as shown in Fig.1. For example, there is a deflective load acted on tunnel when tunnel comes through slope, this loading condition will result in compressive failure, as shown in Fig.1 (c).

From the numerical simulation result, it shows that the load-carrying capacity and deformation behavior of concrete tunnel would be overestimated, if the compressive yielding of concrete and compressive strain softening were not considered, as shown in Fig.2. The experimental device, finite element numerical analytical model and detailed material parameters refer to the part of numerical simulation of this paper.

From the occurrence of compressive failure in practical concrete tunnel services as well as results from the numerical simulation, the compressive behavior of concrete should be considered. In this paper, the compressive models based on total strain will be discussed.

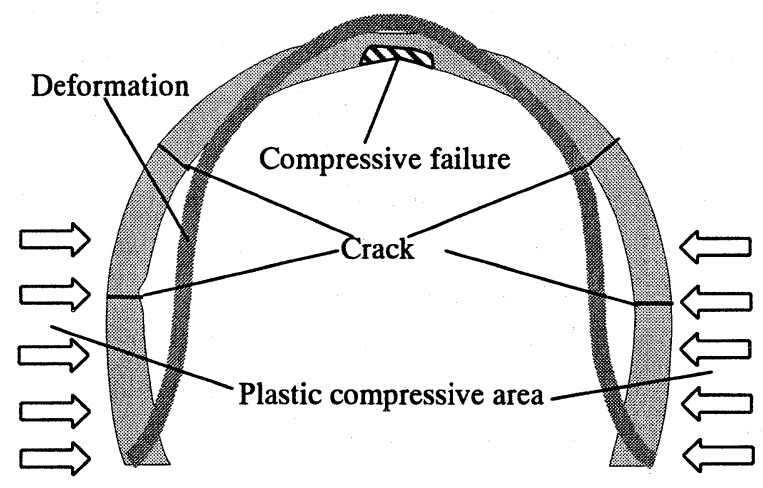

(a) Plastic compressive failure

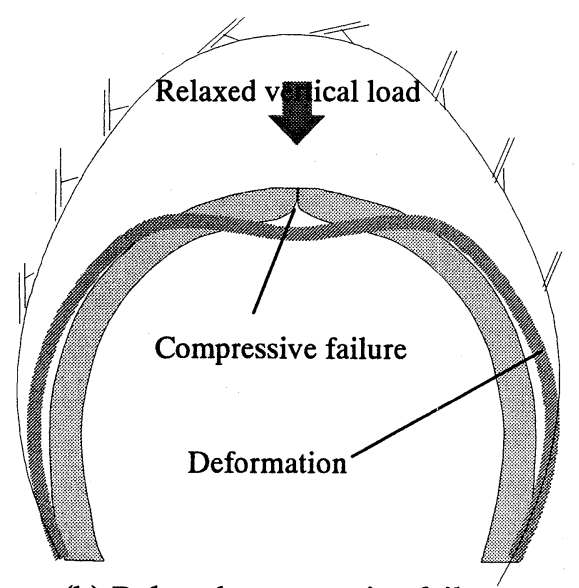

(b) Relaxed compressive failure

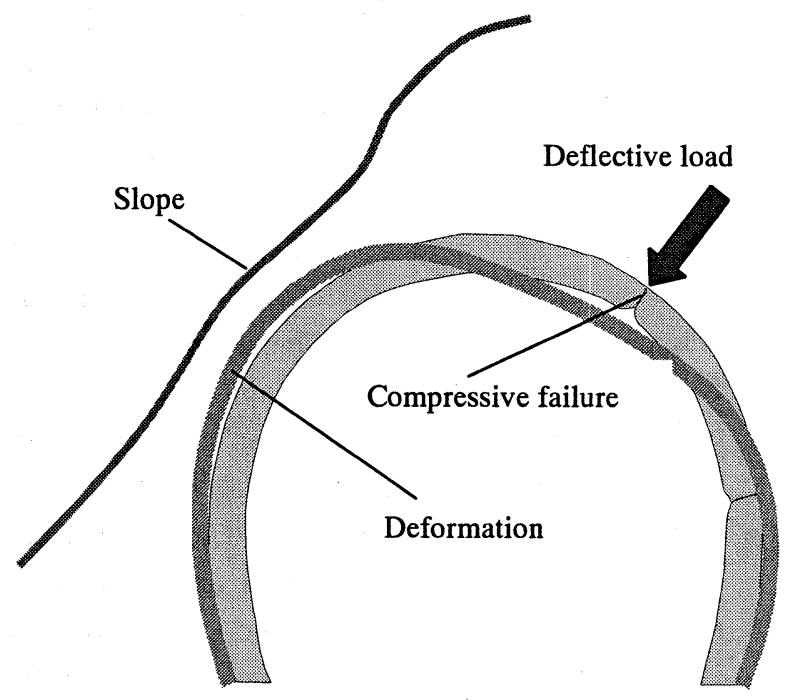

(c) Deflective compressive failure

Fig.1 Compressive failure modes of concrete tunnel

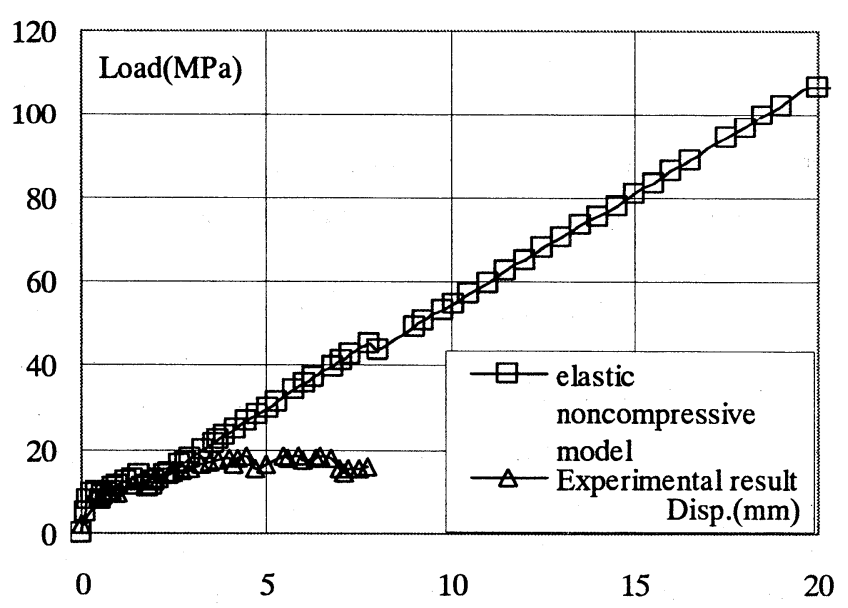

Fig.2 Load-displacement curve of concrete tunnel without compressive model considered

\section{Concrete Material Model}

In this paper, the concrete material model based on total strain describes the stress as a function of the strain. 
This concept of a stress-strain relation can be used not only for nonlinear behavior and crushing in compression, but also for softening or stiffening in tension, and gives a natural combination of cracking and crushing. This model is developed along the lines of the Modified Compression Field Theory, originally proposed by Vecchio and Collins ${ }^{3)}$. The three-dimensional extension to this theory is proposed by Selby and Vecchio.

\subsection{Compressive Behavior for Concrete}

In compression part, two models are discussed. One is the ideal elastic-plastic compressive model based on total strain, in which the compressive stress keeps constant after the compressive strength $f^{\prime}{ }_{c}$ is achieved. The other model, called parabolic compressive softening model, consider the compression strain softening as shown in Fig.3.

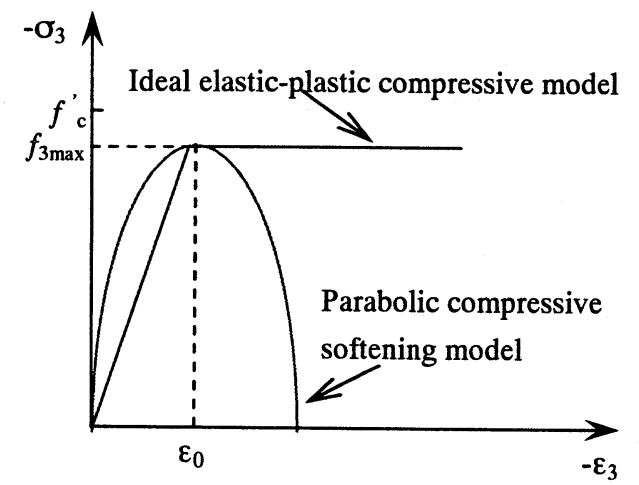

Fig.3 Concrete in compression

For concrete in the direction of the largest principal compressive strain $\left(\varepsilon_{3}\right)$, in case of parabolic compressive softening the stress-strain relation used is

$$
\sigma_{3}=f_{3 \max }\left[2\left(\frac{\varepsilon_{3}}{\varepsilon_{0}}\right)-\left(\frac{\varepsilon_{3}}{\varepsilon_{0}}\right)^{2}\right]
$$

where

$$
f_{3 \max }=\frac{f_{c}^{\prime}}{0.8-\left(0.34 \frac{\varepsilon_{1}}{\varepsilon_{0}}\right)}
$$

and where $f^{\prime}{ }_{c}$ is concrete compressive strength; $\varepsilon_{0}$ is a function of compressive fracture energy; and $E$ is concrete Young's modulus. The reduction in the maximum attainable stress $f_{3 \max }$, as a function of the coexisting transverse tensile strain $\varepsilon_{1}$, typically represents a significant softening effect.

Among these two compressive models, parabolic compressive softening model is based on compressive fracture energy $G_{c}$. Although it is known that numerical analysis result is mesh independent when compressive fracture energy is adopted as material property, the mesh sensitivity will be still discussed in this paper.

\subsection{Tensile Behavior for Concrete}

In tension part, the conventional linear softening stress-strain relation is adopted, as shown in Fig.4. The cracking behavior based on total strain treated cracked concrete as an orthotropic path-independent material based on a smeared, rotating crack model ${ }^{4}$. Conditions of equilibrium and compatibility were treated in terms of average stresses and average strains. Local stress conditions at crack locations were also considered.

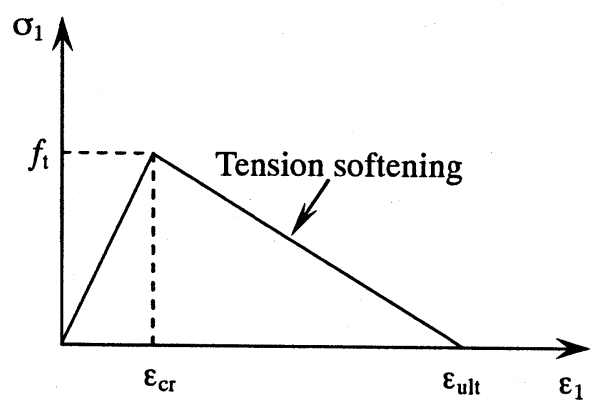

Fig. 4 Concrete in tension

For concrete in the direction of the principal tensile strain $\left(\varepsilon_{1}\right)$, prior to concrete cracking, a linear relation is used

$$
\sigma_{1}=E \varepsilon_{1}, \quad 0<\varepsilon_{1}<\varepsilon_{c r}
$$

where

$$
\varepsilon_{c r}=\frac{f_{t}}{E}
$$

and $f_{\mathrm{t}}$ is concrete tensile strength.

After cracking, in case of linear tensile softening the decaying function

$$
\sigma_{1}=f_{t}\left(1-\frac{\varepsilon_{1}}{\varepsilon_{u l t}}\right), \quad \varepsilon_{c r}<\varepsilon_{1}<\varepsilon_{u l t}
$$

is used to reflect the tension-stiffening effects that are important in accurately predicting an element's load-deformation response. The ultimate crack strain $\varepsilon_{\text {ult }}$ is a function of tensile fracture energy.

\subsection{Constitutive Equation}

Currently, in the absence of a complete three-dimensional model, the intermediate principal stress $\sigma_{2}$ is evaluated using the same relationships. Thus, if $\varepsilon_{2}$ is compressive, then (1)-(2) are used substituting $\varepsilon_{2}$ for $\varepsilon_{3}$; if $\varepsilon_{2}$ is tensile, then (3)-(5) are used.

In developing the stiffness formulations for a finite element, a material stiffness matrix $\mathbf{D}$ is required to relate stresses $\{\sigma\}$ to strains $\{\varepsilon\}$, that is 


$$
\{\boldsymbol{\sigma}\}=\mathbf{D}\{\boldsymbol{\varepsilon}\}
$$

where $\{\sigma\}=\left[\sigma_{x} \sigma_{y} \sigma_{z} \tau_{x y} \tau_{y z} \tau_{x z}\right]$; and $\{\varepsilon\}=\left[\varepsilon_{x} \varepsilon_{y} \varepsilon_{z} \gamma_{x y} \gamma_{y z} \gamma_{x z}\right]$.

The form of the matrix $\mathbf{D}$ will depend on the type of nonlinear solution algorithm employed. The formulations that follow assume a secant-stiffness approach. This approach is according to the stiffness of an orthotropic material with zero Poisson's ratio in all directions. Thus, the concrete material stiffness matrix evaluated with respect to the principal coordinate system, $\mathbf{D}_{\text {secant }}$, is

$$
D_{\text {sec } a n t}=\left[\begin{array}{cccccc}
\bar{E}_{1} & 0 & 0 & 0 & 0 & 0 \\
0 & \bar{E}_{2} & 0 & 0 & 0 & 0 \\
0 & 0 & \bar{E}_{3} & 0 & 0 & 0 \\
0 & 0 & 0 & \bar{G}_{12} & 0 & 0 \\
0 & 0 & 0 & 0 & \bar{G}_{23} & 0 \\
0 & 0 & 0 & 0 & 0 & \bar{G}_{31}
\end{array}\right]
$$

where $\bar{E}_{1}, \bar{E}_{2}, \bar{E}_{3}, \bar{G}_{12}, \bar{G}_{23}, \bar{G}_{31}$ are defined as follows:

$$
\begin{gathered}
\bar{E}_{1}=\frac{\sigma_{1}}{\varepsilon_{1}} \\
\bar{E}_{2}=\frac{\sigma_{2}}{\varepsilon_{2}} \\
\bar{E}_{3}=\frac{\sigma_{3}}{\varepsilon_{3}} \\
\bar{G}_{12}=\frac{\bar{E}_{1} \bar{E}_{2}}{\bar{E}_{1}+\bar{E}_{2}} \\
\bar{G}_{23}=\frac{\bar{E}_{2} \bar{E}_{3}}{\bar{E}_{2}+\bar{E}_{3}} \\
\bar{G}_{31}=\frac{\bar{E}_{1} \bar{E}_{3}}{\bar{E}_{1}+\bar{E}_{3}}
\end{gathered}
$$

where $\sigma_{1}, \sigma_{2}, \sigma_{3}$ are principal stresses; and $\varepsilon_{1}, \varepsilon_{2}, \varepsilon_{3}$ are principal strains in the first, second, and third directions respectively.

The material stiffness $\mathbf{D}_{\text {secant }}$ is evaluated with respect to the principal axes systems. So it must be transformed to the global axes system. The transformation required is as follows:

$$
\mathbf{D}=\mathbf{T}^{\mathrm{T}} \mathbf{D}_{\text {secant }} \mathbf{T}
$$

Where the transformation matrix $\mathbf{T}$ is given (Cook 1981) by

$\mathbf{T}=\left[\begin{array}{cccccc}l_{1}^{2} & m_{1}^{2} & n_{1}^{2} & l_{1} m_{1} & m_{1} n_{1} & n_{1} l_{1} \\ l_{2}^{2} & m_{2}^{2} & n_{2}^{2} & l_{2} m_{2} & m_{2} n_{2} & n_{2} l_{2} \\ l_{3}^{2} & m_{3}^{3} & n_{3}^{2} & l_{3} m_{3} & m_{3} n_{3} & n_{3} l_{3} \\ 2 l_{1} l_{2} & 2 m_{1} m_{2} & 2 n_{1} n_{2} & l_{1} m_{2}+l_{2} m_{1} & m_{1} n_{2}+m_{2} n_{1} & n_{1} l_{2}+n_{2} l_{1} \\ 2 l_{2} l_{3} & 2 m_{2} m_{3} & 2 n_{2} n_{3} & l_{2} m_{3}+l_{3} m_{2} & m_{2} n_{3}+m_{3} n_{2} & n_{2} l_{3}+n_{3} l_{2} \\ 2 l_{3} l_{1} & 2 m_{3} m_{1} & 2 n_{3} n_{1} & l_{3} m_{1}+l_{1} m_{3} & m_{3} n_{1}+m_{1} n_{3} & n_{3} l_{1}+n_{1} l_{3}\end{array}\right]$

The direction cosines $l, m, n$ define the direction of the principal concrete strains.

\section{Experimental Review ${ }^{5}$}

In order to investigate the cracking and failure mechanism of concrete tunnel lining, a series of $1 / 30$ model tests was carried out by the Railway Technical Institute of Japan. For the practical stress state, the loading conditions include not only concentrated force, but also the soil constraint outside the tunnel linings, therefore this experimental study gave more care about the interaction between concrete tunnel lining and surround soil.

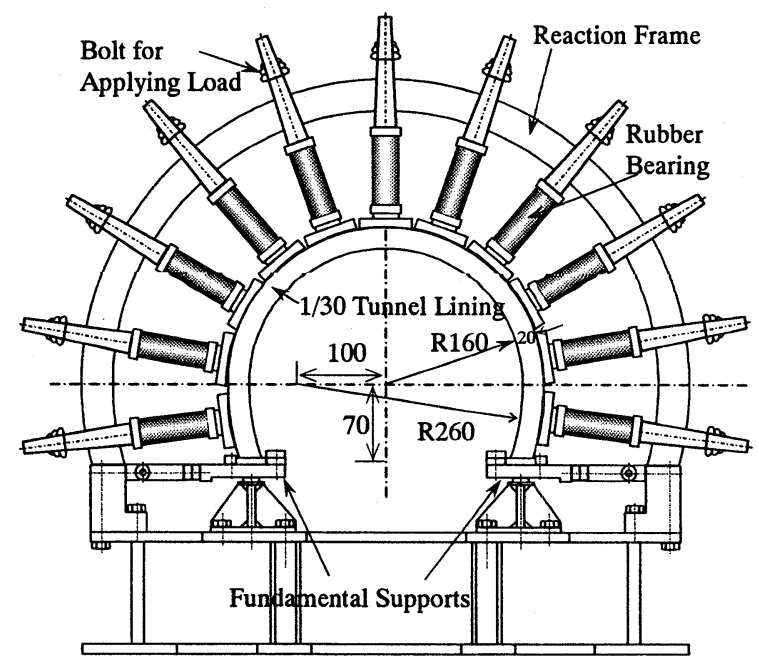

Fig.5 Concrete tunnel specimen and experimental setup (dimension: $\mathrm{mm}$ )

To take account of surrounding soil constraint, a kind of constraining equipment is used in the test to simulate the outside soil, as illustrated in Fig.5. The rubber bearings that are set outside the tunnel lining provide constraint to the outward deformation. The horizontal direction of the tunnel lining at the foot is fixed by the 
Table 1 Different finite element meshes for beam

\begin{tabular}{|c|c|c|c|c|}
\hline Mesh cases & Element type & $\begin{array}{c}\text { Element number along } \\
\text { length direction of beam }\end{array}$ & $\begin{array}{c}\text { Element number along } \\
\text { height direction of beam }\end{array}$ & $\begin{array}{c}\text { Total } \\
\text { element } \\
\text { number }\end{array}$ \\
\hline Mesh10_beam & $\begin{array}{c}\text { 4-node quadrilateral } \\
\text { plane stress element }\end{array}$ & 106 & 10 & 1060 \\
\hline Mesh20_beam & $\begin{array}{c}\text { 4-node quadrilateral } \\
\text { plane stress element }\end{array}$ & 210 & 20 & 4200 \\
\hline Mesh20*_beam & $\begin{array}{c}\text { 8-node quadrilateral } \\
\text { plane stress element }\end{array}$ & 210 & 20 & 4200 \\
\hline
\end{tabular}

Table 2 Finite element mesh cases for concrete tunnel

\begin{tabular}{|c|c|c|c|c|c|}
\hline Mesh cases & $\begin{array}{c}\text { QU4 element number } \\
\text { along perimeter } \\
\text { direction of tunnel }\end{array}$ & $\begin{array}{c}\text { QU4 element number } \\
\text { along radius direction } \\
\text { of tunnel }\end{array}$ & $\begin{array}{c}\text { Total QU4 } \\
\text { element } \\
\text { number }\end{array}$ & $\begin{array}{c}\text { Total interface } \\
\text { element } \\
\text { number }\end{array}$ & $\begin{array}{c}\text { Total } \\
\text { element } \\
\text { number }\end{array}$ \\
\hline Mesh8_tunnel & 276 & 8 & 2208 & 276 & 2484 \\
\hline Mesh10_tunnel & 338 & 10 & 3380 & 338 & 3718 \\
\hline Mesh12_tunnel & 402 & 12 & 4824 & 402 & 5226 \\
\hline Mesh20_tunnel & 638 & 20 & 12760 & 638 & 13398 \\
\hline \multicolumn{5}{|c|}{ QU4 denotes 4-node quadrilateral plane stress element } \\
\hline
\end{tabular}

stopper made from steel. The external load is acted vertically at the outside crown, which is transferred by a steel bolt from the oil pressure load machine to the tunnel lining specimen.

\section{Numerical Simulation}

Based on the experiments, finite element analysis is performed using DIANA 8.1, focusing on the selection of proper compressive models. Concrete tunnel lining is discretized by plane stress elements as shown in Fig.6.

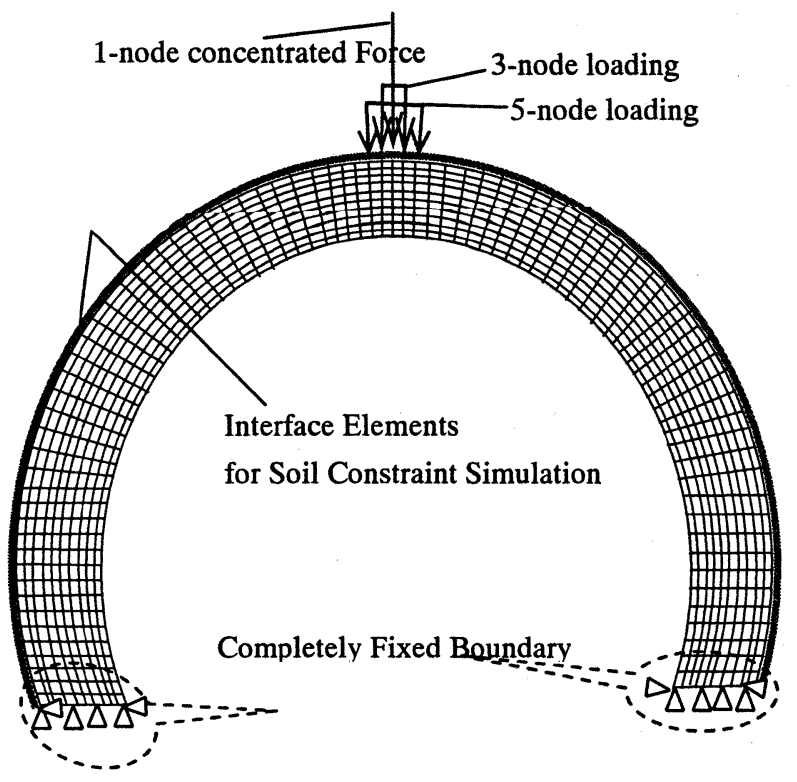

Fig.6 Tunnel mesh for finite element analysis
Two types of element are introduced to simulate the concrete tunnel. One is 4-node quadrilateral plane stress element for concrete; the other is interface element to simulate the soil constraint outside the concrete tunnel.

The detailed parameters used in the numerical simulation are described as follows. Concrete Young's modulus is $E_{c}=1.5 \times 10^{4} \mathrm{MPa}$, Poisson ratio is $v=0.15$, tensile strength is $f_{t}=2.0 \mathrm{MPa}$, mode I fracture energy is $G_{I}=0.1 \mathrm{~N} / \mathrm{mm}$, compressive strength is ${f^{\prime}}_{c}=22.0 \mathrm{MPa}$. For parabolic softening compressive model, the compressive fracture energy $G_{c}$ is set as $2.0 \mathrm{~N} / \mathrm{mm}$. The stiffness of interface element that simulates the soil constraint is $K_{c}=0.11 \mathrm{~N} / \mathrm{mm}^{3}$.

\subsection{Investigation of mesh sensitivity of concrete compressive model}

\section{(1) Case of a reference beam}

During the numerical analyses, it seems that analytical results are mesh-dependent. Because the concrete compressive models, which are discussed in this paper, are based on total strain, hence one simple case of a reference beam is studied first.

In Fig. 7 the material and geometry parameters used in the numerical analysis are given as follows. Young's modulus is $E_{c}=1.5 \times 10^{4} \mathrm{MPa}$, Poisson ratio is $v=0.15$, compressive strength is $f_{c}^{\prime}=22.0 \mathrm{MPa}$, width is $1.0 \mathrm{~cm}$. Cross section of the beam is rectangular section. The ideal elastic-plastic compressive model based on total 
strain is applied, while the tension behavior of concrete is regarded as elasticity.

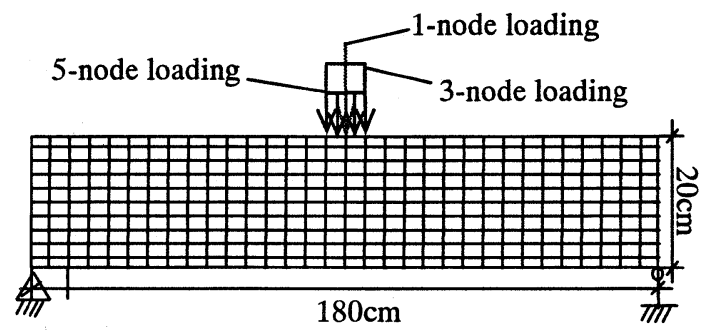

Fig.7 Different loading cases of a reference beam

In Fig. 8 the numerical analytical results show that the ultimate load is mesh-dependent with both linearly interpolated four-node quadrilateral isoparametric plane stress element and the quadratically interpolated eight-node quadrilateral isoparametric plane stress element.

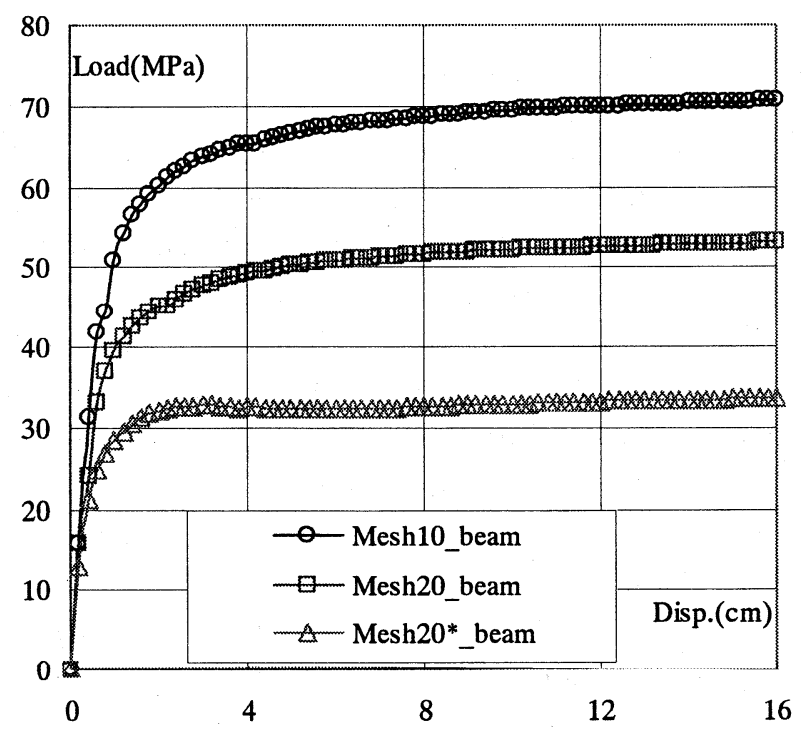

Fig.8 Mesh sensitivity of ideal elastic-plastic compressive model with 1-node loading on the beam

As shown in Fig.9, the large deformation happened in only one single element of which the node was being acted on concentrated load, such as Mesh10_beam, Mesh20_beam and Mesh20*_beam, this would be result in spurious numerical destruction. To avoid the numerical spurious destruction, one solving method is to apply distributed load in a small range, as shown in Fig.7, instead of 1-node concentrated load. For Mesh10_beam, Mesh20_beam and Mesh20*_beam, the acting range of both 3-node loading and 5-node loading is coincident.

Applied with the 3-node loading or 5-node loading, the numerical analytical result of ultimate load is almost the same. At the same time, the influence of mesh sensitivity is eliminated, as shown in Fig.10.

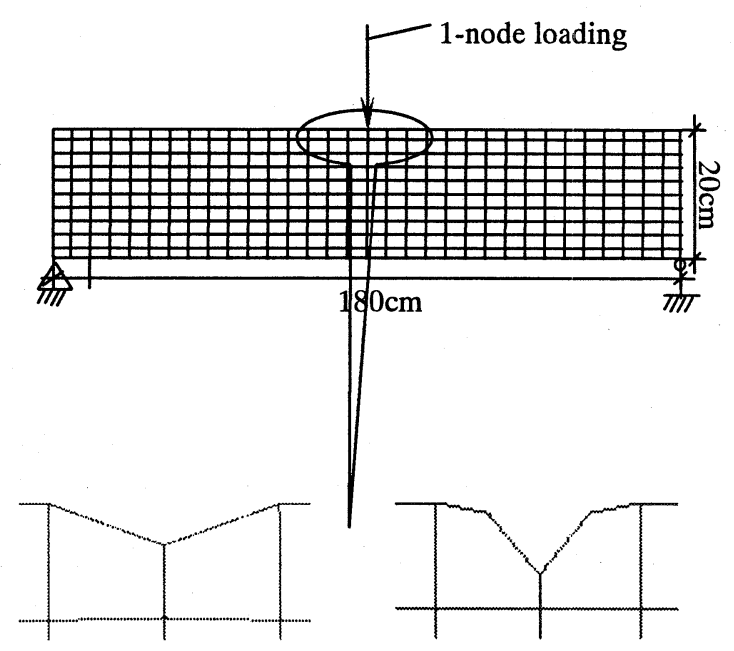

(a) Mesh10 beam

(b) Mesh20_beam

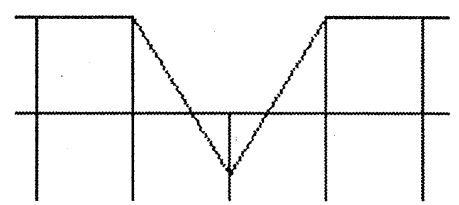

(c) Mesh20*_beam

Fig.9 Mesh deformation near the concentrated load

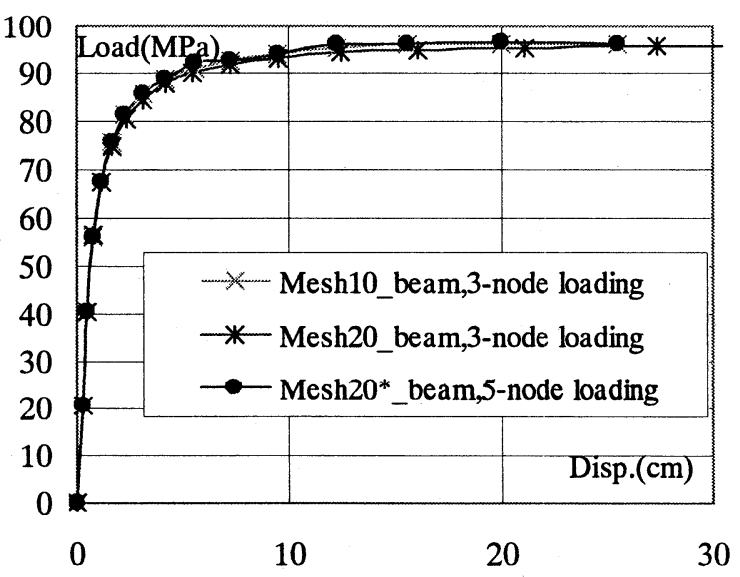

Fig.10 Mesh sensitivity of ideal elastic-plastic model with distributed load on the beam

(2) Case of concrete tunnel simulated with ideal elastic-plastic compressive model

When 1-node concentrated force is applied to concrete tunnel and ideal elastic-plastic compressive model is adopted, it is found that the load-carrying capacity is also mesh-dependent, as shown in Fig.11. 1-node concentrated force is illustrated in Fig.6.

As a special notice, the acting range of 3-node loading, which applies to the Mesh8_tunnel, Mesh10_tunnel and Mesh12_tunnel, is kept same. 
Actually, the external force that is applied by 3-node loading, namely, is distributed load. But the acting range of 5-node loading is larger than that of 3-node loading, as shown in Fig.6.

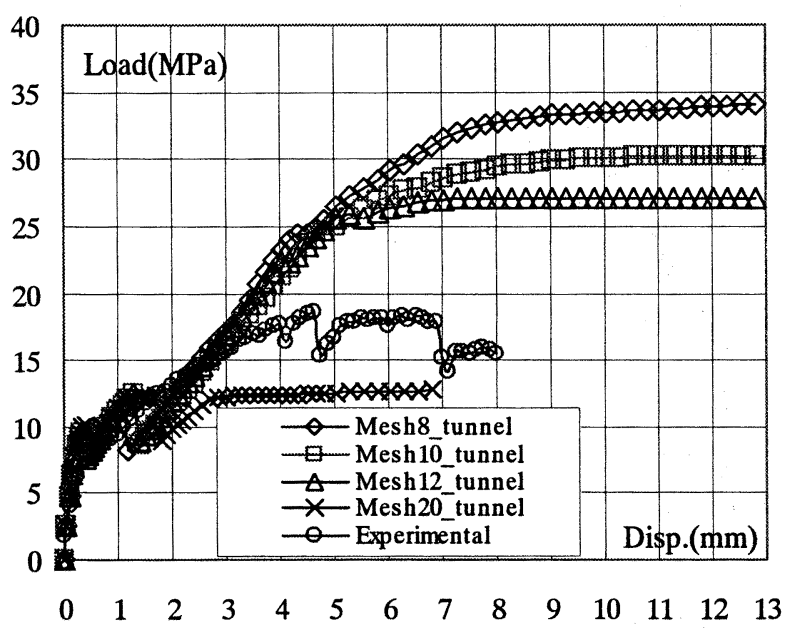

Fig.11 Mesh sensitivity of ideal elastic-plastic compressive model on concrete tunnel (1-node concentrated force)

By changing loading pattern from 1-node concentrated force to 3-node distributed load, the mesh sensitivity of concrete tunnel simulated with ideal elastic-plastic compressive model would be avoided. The load and displacement relation is given in Fig.12.

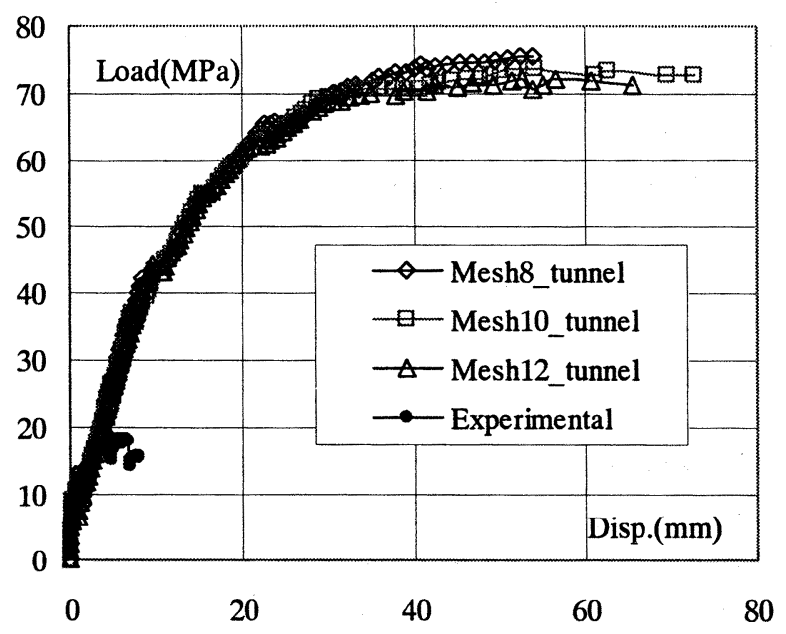

Fig.12 Mesh sensitivity of concrete tunnel simulated with ideal elastic-plastic compressive model (3-node loading)

In Fig.13 the load-carrying capacity of concrete is different when the range of applied distributed load is not coincident. The load-carrying capacity which is obtained from 1-node concentrated force is not proper, because the excessive element deformation results in the numerical computation crash before the yielding compressive region comes into being stably, as shown in Fig.14.

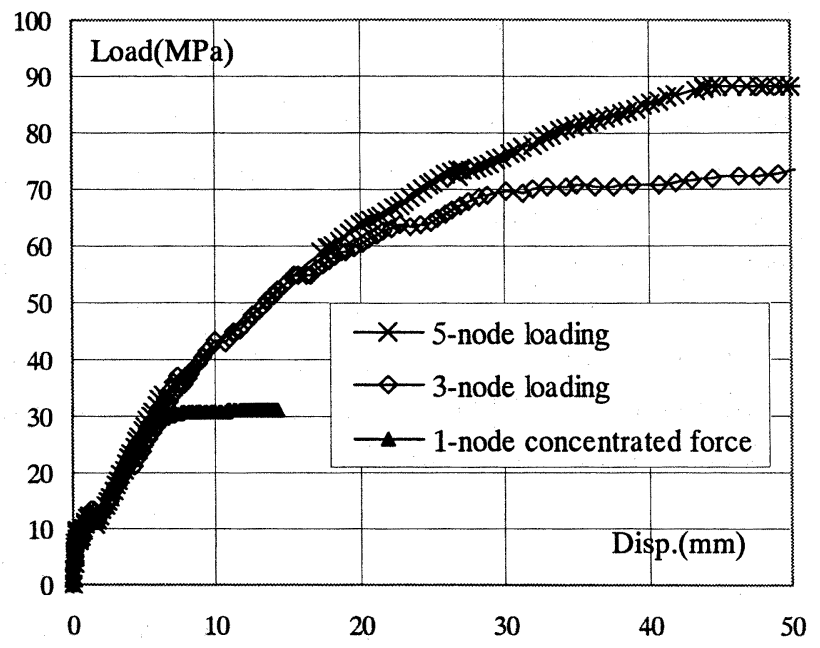

Fig.13 Loading patterns of concrete tunnel with ideal elastic-plastic compressive model (Mesh10_tunnel)

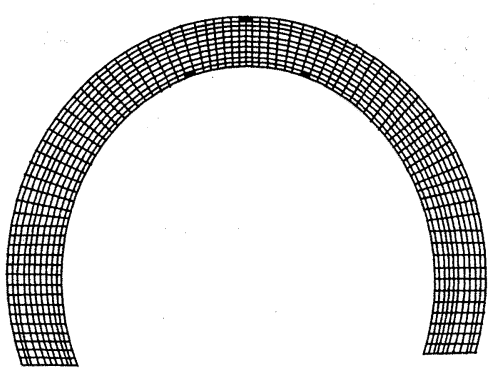

(a) 1-node concentrated force

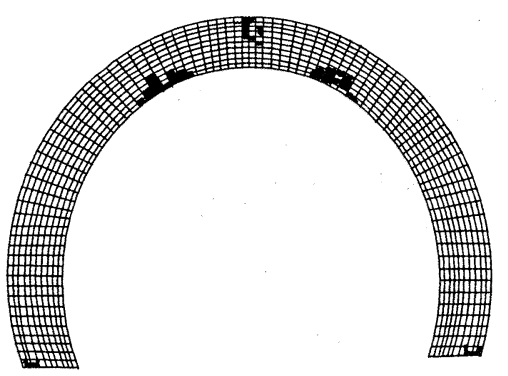

(b) 3-node loading

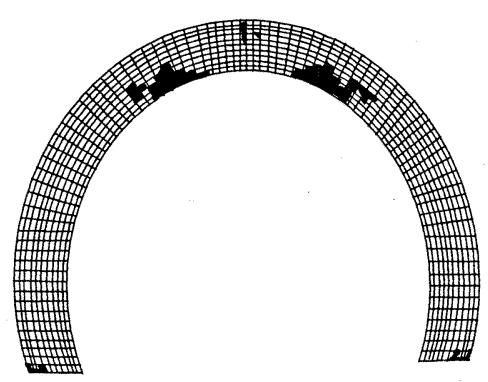

(c) 5-node loading

Fig.14 Compressive yielding region and loading patterns (Mesh10_tunnel) 
In Fig.14, the compressive yielding region in case of 5-node loading is larger than that in case of 3-node loading, and this makes the load-carrying capacity with 5-node loading higher.

\subsection{Parabolic compressive softening model}

In Fig.15 and Fig.16, ' $A$ ' means that the first crack occurred in the crown (inside) followed by ' $B$ ' which are outside cracks at the sidewalls. The structural deformation increased immensely after the crack occurred at the inside of crown. But the concrete tunnel lining could still resist the external load until the concrete crushing happened at the top of the tunnel.

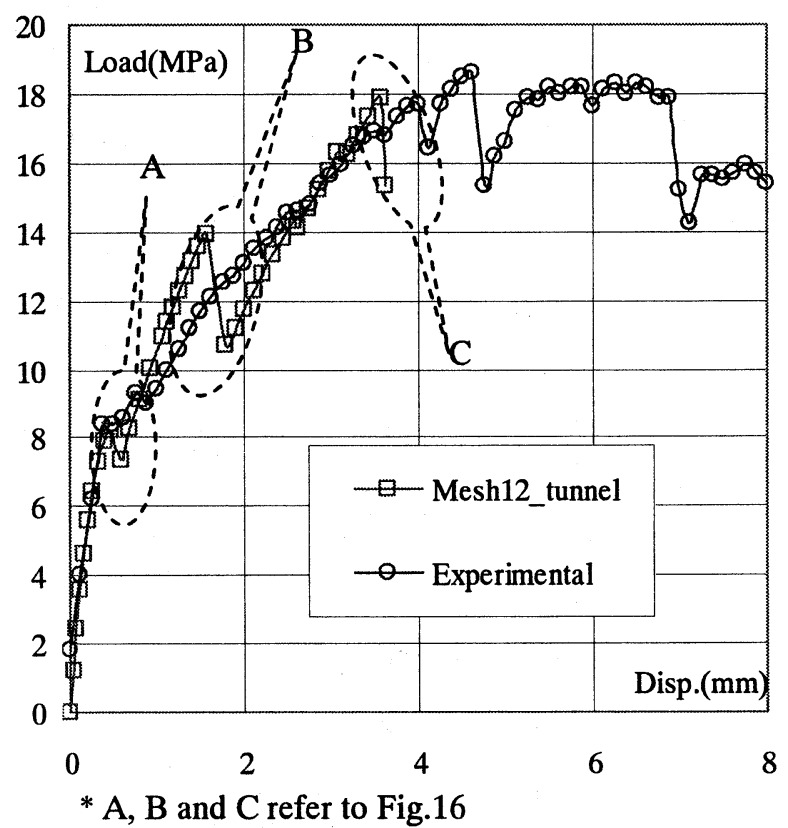

Fig.15 Effect of parabolic compressive softening model (3-node loading)

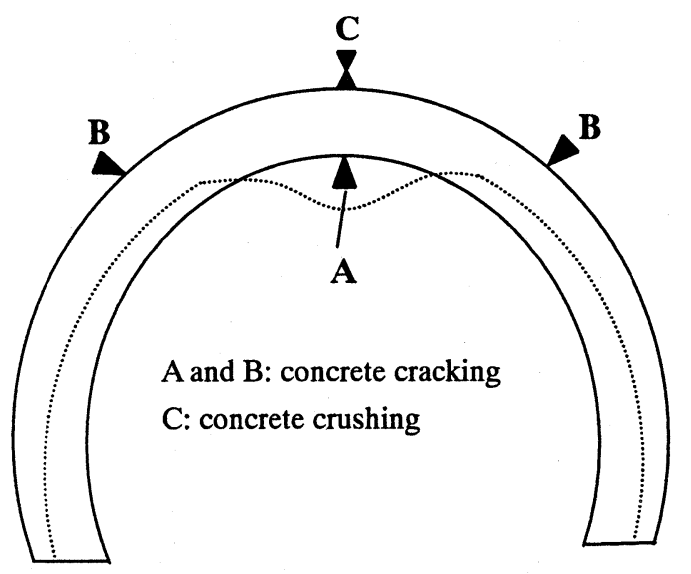

Fig.16 Location of cracking and crushing

The mesh sensitivity of parabolic compressive softening model is checked in Fig.17. It shows that there is no obvious mesh sensitivity, so in the latter cases only
Mesh12_tunnel of finite element mesh is used and 3-node loading is applied.

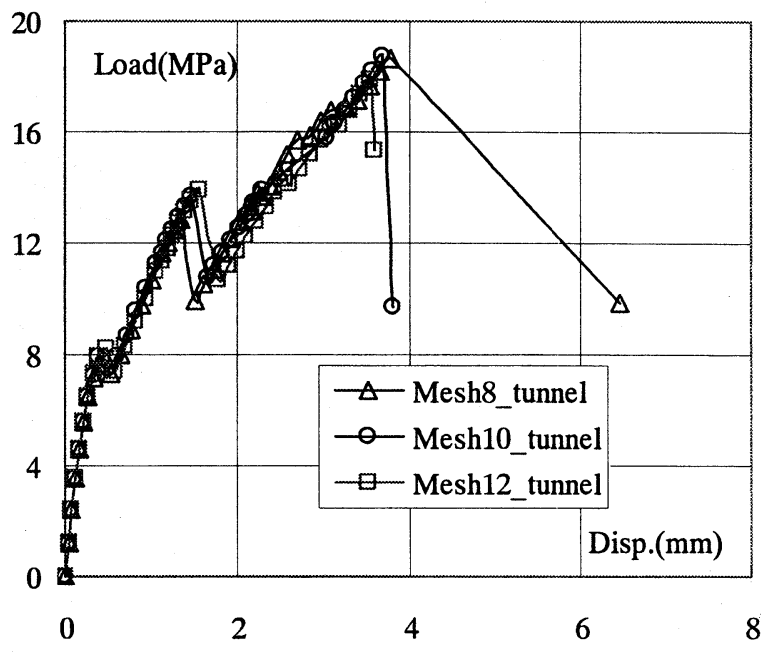

Fig.17 Mesh sensitivity of parabolic compressive model on concrete tunnel (3-node loading)

The numerical simulation results of load-displacement relationship that compared with the experimental one in Fig.12 and Fig.15, shows that the ideal elastic-plastic compressive model has the highest peak load while the lower ones are obtained by using the parabolic compressive softening model. Compared with the experimental result, the ideal elastic-plastic compressive model seems to overestimate the load-carrying capacity of the concrete tunnel lining as well as deformation capacity, although it is better than elastic non-compressive models for analyzing concrete tunnel with soil constraint, but the parabolic compressive softening model approaches the test most. Hence, the parabolic softening model for compression is considered to be a proper model.

\section{(1) Effect of compressive fracture energy}

Many researchers have considered the compressive fracture energy, $G_{c}$, as a material property. But due to the lack of information of this property, herein, cases with compressive fracture energy $G_{c}=2.0,4.0,6.0$, $1000000.0 \mathrm{~N} / \mathrm{mm}$ are studied. The concrete compressive strength is kept constant, as $f^{\prime}{ }_{c}=22.0$ $\mathrm{MPa}$.

In Fig.18 the higher the compressive fracture energy is taken, the higher structural strength can be archived.

Based on Fig.3 when compressive fracture energy's value of parabolic compressive model is up to infinite and compressive strength of these two models keeps same, in theory it can be concluded that the numerical analytical results simulated by parabolic compressive 
model is the same as that simulated by ideal elastic-plastic compressive model, as shown in Fig.19.

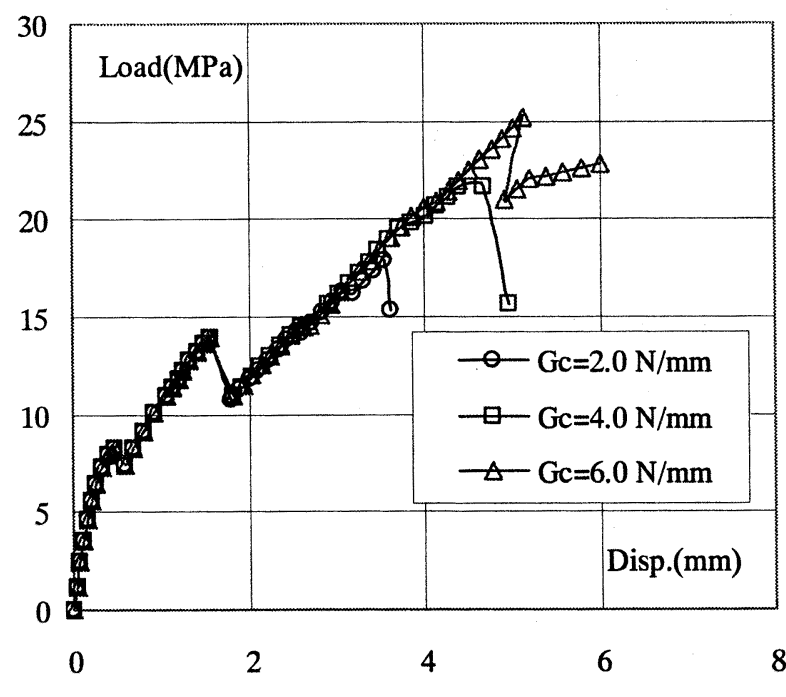

Fig.18 Parabolic compressive model with different compressive energy

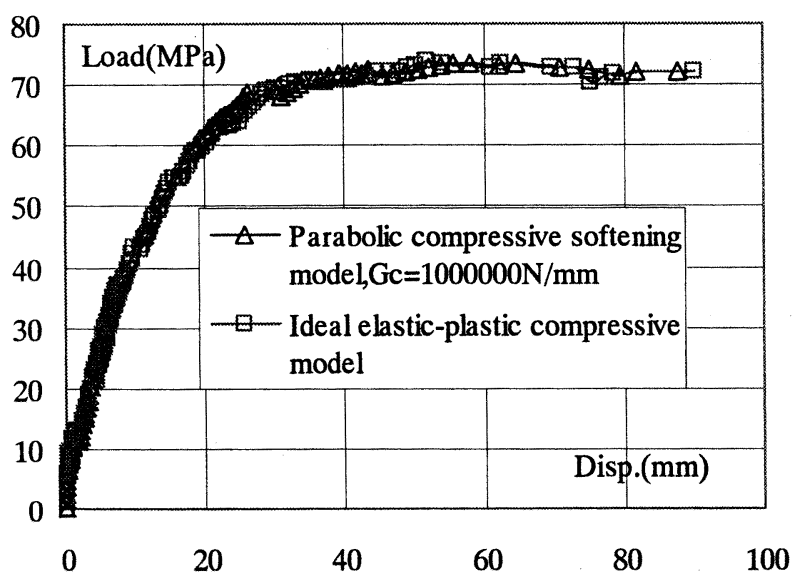

Fig.19 Ideal elastic-plastic and parabolic compressive model

\section{Conclusions}

By considering different compressive models based on total strain, some numerical simulations have been done to investigate the cracking and crushing behavior of $1 / 30$ scale model of concrete tunnel lining. From the cases studies in several aspects it can be concluded that:

(1) The soil constraint outside concrete tunnel plays an important role in controlling the deformation of concrete as well as the crack propagation. Under certain soil constraint, tensile cracking is not a dominated failure mode. The final failure will be depend on the compressive behavior of concrete.

(2) For a rational compressive concrete model, it needs to evaluate the load-carrying capacity of tunnel linings and compressive behavior of concrete correctly. It is shown that parabolic compressive softening model by considering the compressive fracture energy is more appropriate to simulate the compressive behavior of concrete tunnel than ideal elastic-plastic compressive model through the numerical analysis and comparison with experimental results.

(3) Mesh dependence is obvious from the compressive strain, in this paper by changing the loading pattern from concentrated load to distributed load on a small range, mesh sensitivity would be avoided. At the same time, during the numerical simulation analysis the distributed load acting on a small range is more accordant with the actual experimental loading condition.

(4) The parameter studies of concrete compressive fracture energy shows that the compressive fracture energy affects the structural strength. The higher the compressive fracture energy is given, the higher structural strength can be archived.

\section{References}

1) Asakura, T., Ando, T., Omata, F., Wakana, K. and Matsuura, A.: Behavior of structurally defective tunnel lining and effectiveness of inner reinforcement, Journal of Geotechnical Engineering, JSCE, No.493, 1994.6, pp.89-98.

2) Yin, J., Wu, Z.S., Asakura, T. and Ota, H.: Cracking and Failure Behavior of Concrete Tunnel Lining Predicted by Smeared Crack Model, Journal of Struc. Mech. and Earthquake Eng., JSCE, Vol.18, No.1, 2001.1, pp.17-27.

3) Vecchio, F. J., and Collins, M. P. The modified compression field theory for reinforced concrete elements subjected to shcar. ACI Journul, Proceedings, Vol.83, No.2, 1986.3-4, pp.219-231.

4) Vecchio, F. J., and Selby, R. G. Toward Compression-Field Analysis of Reinforced Concrete Solids. Journal of Structural Engineering, Vol.117, No.6, 1991.6, pp.1740-1758.

5) Asakura, T., Ando, T. and Kojima, Y.: Experiments of inner reinforced tunnel linings, $Q R$ of $R T R I$, 1998. 